\title{
Evaluation of impact of immunocytochemical techniques in cytological diagnosis of neoplastic effusions
}

\author{
ALESSANDRA LINARI, G BUSSOLATI \\ From the Department of Biomedical Sciences and Human Oncology, University of Turin, Italy
}

SUMMARY A prospective study (1984-87) on the immunocytochemical identification of cancer cells $\overrightarrow{\vec{\omega}}$ in effusions using HMFG2 monoclonal antibody, and in addition, monoclonal anti-CEA and B72.3 antibodies in cases of suspected mesothelioma, was undertaken. On the basis of cytology alone, of a ? total of 2362 pleural, peritoneal, and pericardial effusions, 525 cases were diagnosed as positive and ${ }^{\text {N }}$ 1485 as negative for neoplastic cells, while in $352(15 \%)$ specimens from 307 patients the diagnosis $\overrightarrow{-}$ was doubtful. Sections of the embedded sediment of doubtful cases were tested with HMFG2 antibody and proved positive in 215 cases, negative in 108, and inconclusive in 29. The results were $\stackrel{\infty}{\oplus}$ checked by following the clinical outcome of the cases. The method was specific in identifying cancer $ᄋ$ cells in cases at best diagnosed as suspicious on the basis of cytology alone; this represents a clear diagnostic gain. Sensitivity of the test, however, was relatively low $(41 \%)$. Combined cytological and immunocytochemical characteristics (CEA negative and only some of the neoplastic cells positive with HMFG2 and B72.3 monoclonal antibodies) permitted diagnosis on the effusions of most cases of mesothelioma.

The impact of the diagnosis on the progress of the disease was not appreciable as no difference in $\vec{\theta}$ outcome was noted, irrespective of whether cancer cells had been recognised. The occurrence of a a effusion remains an ominous sign in most patients treated for cancer.

The diagnosis of pleural, peritoneal and pericardial effusions remains one of the most difficult tasks in diagnostic cytology, ${ }^{1}$ yet it is of paramount importance for determining the nature, either reactive or neoplastic, of the underlying disease.

The diagnosis is made on smears or embedded sediments and is based on classical morphological criteria, the most difficult problem being the differentiation of neoplastic cells from reactive mesothelial cells. $^{2}$ The latter, which occur either singly or arranged in small clusters, have, in fact, an epithelial appearance and often show rather large and hyperchromatic nuclei, related to their hyperplastic nature. ${ }^{3}$ Neoplastic cells, on the other hand, especially breast cancer cells, can look benign and do not always show highly atypical nuclei. Cases therefore arise in which doubtful diagnoses are given, even by experienced pathologists. False negative and occasionally false positive cases are reported. ${ }^{4-6}$

Immunocytochemistry has been advocated as helpful, especially in solving doubtful cases. Several markers have been proposed to identify cancer cells and to differentiate them from reactive mesothelial cells. ${ }^{15-15}$

Since 1983, after reports on the diagnostic useful-

Accepted for publication 12 June 1989 ness of immunocytochemical staining with HMFG2 monoclonal antibody to detect cancer cells in effusions, ${ }^{51016}$ we have been using such tests to identify cancer cells in critical cases observed in daily diagnostic practice. These cases, amounting to a total of 352 (from 307 patients), represented $13 \%$ of a total of 2362 serous effusions, examined between 1984 and 1987 inclusive. We have now tested the clinical use of the immunocytochemical test by checking the clinical outcome of the cases.

\section{Material and methods}

The effusion samples arriving at the cytology laboratory of this department were all routinely processed by centrifugation, followed by smearing and treatment of the sediment by fixation in $95 \%$ ethanol and paraffin wax embedding using the "cell bag" procedure ${ }^{17}$ in common use in this laboratory for the past seven years. Smears were stained by the Papanicolaou method, and paraffin wax sections were stained by haematoxylin and eosin and, in selected cases, with periodic acid Schiff (PAS) with or without diastase treatment.

Immunoperoxidase staining was performed on paraffin wax sections of the embedded sediment. 
Endogenous peroxidase was blocked by hydrogen peroxide-periodic acid-sodium periodate treatment. ${ }^{18}$ After a short treatment with non-immune serum the sections were treated overnight at room temperature with HMFG2 (kindly supplied, as culture supernatant, by Dr Taylor-Papadimitriou, ICRF, London) at a 1/200 dilution. The characteristics of this monoclonal antibody were originally reported by Arklie $e t$ al. ${ }^{19}$ Biotinylated anti-mouse immunoglobulin antiserum (from horse) and avidin-biotin peroxidase complexes $^{20}$ were then used according to the ABC procedure. The colour reaction was developed with $\mathrm{H}_{2} \mathrm{O}_{2}$-DAB. Nuclei were counterstained with haemalum. Sections of breast, lung, and colorectal adenocarcinomas were used as positive controls. Additional controls were cytologically positive effusion sediments from carcinomas of the breast (10 cases) and cytologically negative cases from patients with clinically confirmed non-neoplastic diseases (cyrrhosis, four cases; heart failure, three cases; pleuritis, two cases; peritonitis, one case). The former were HMFG2 positive, while reactive mesothelial cells were negative.

From 1984 to 1987 inclusive a total of 2362 serous effusions from pleural $(n=1314)$, peritoneal $(n=$ $1009)$, and pericardial $(n=39)$ cavities were examined in this laboratory. In $540(23 \%)$ cases a positive diagnosis for neoplastic cells was made, while in 1515 $(64 \%)$ cases the diagnosis was negative.

In $352(15 \%)$ specimens from 307 patients, no definite diagnosis was reached on morphological criteria alone, and diagnosis was deferred pending immunocytochemical staining. Sections of the embedded sediment were tested with HMFG2. Where mesothelioma was suspected, additional sections were stained with monoclonal antibodies anti-CEA and B72.3 (both from Sorin, Saluggia, at a dilution of $1 / 30$ and $1 / 4$, respectively). In both cases the $A B C$ immunoperoxidase procedure was used. The characteristics of monoclonal B72.3, which detects a carcinomaassociated antigen, have been reported by Nuti et al. ${ }^{9}$

The clinical diagnosis was confirmed in all patients. In some of the cases cytological examination of the effusion sample had been requested as confirmatory in cancer patients, while in other cases with unknown underlying disease its role was diagnostic and therefore more critical. Of the 307 patients, follow up was possible for only 296 , over a minimum of 12 months and a maximum of 48 months (mean 18 months). In these patients we took into consideration both the clinical diagnosis at discharge from the hospital and the outcome of the disease.

To estimate the predictive value, specificity, and sensitivity of the HMFG2 test for recognising the nature of the disease (either neoplastic or reactive), we only considered cases with complete follow up and with certain diagnosis. Cases affected by nonepithelial neoplasias, doubtful immunocytochemical results and patients dead of a disease clinically regarded as non-neoplastic, but which had not undergone necropsy, were excluded.

The sensitivity, specificity, and predictive value of a positive test were calculated according to the method of Galen and Gambino. ${ }^{21}$

\section{Results}

The 352 cases with uncertain cytological diagnosis ( $15 \%$ of the total) were investigated by immunoperoxidase staining with HMFG2, on sections from the embedded sediment parallel to those already stained by the routine procedure. These cases were mostly from patients suspected of having metastases (one third of the cases with breast cancer) but in $20 \%$ of the cases no definite clinical suspicion had been raised. In 34 patients the immunocytochemical test was repeated more than once at different times; in 20 cases (50 tests) the results were always positive, while in 14 (29 tests) they were always negative. No discrepancies were observed.

In effusions from 185 patients (215 tests) cells positively stained by HMFG2 were detected; in the same sections unstained lymphocytes and cells morphologically interpretable as macrophages and

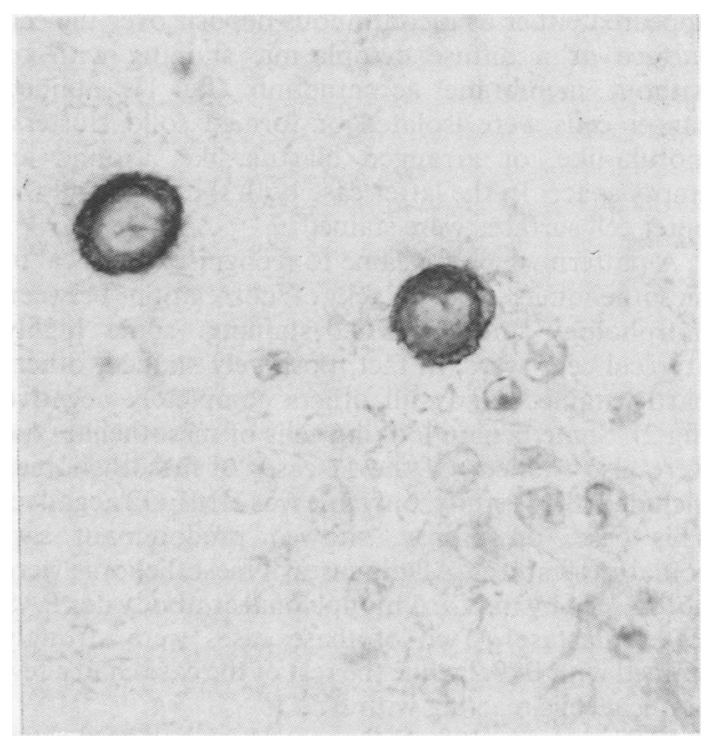

Fig 1 Pleural effusion from a patient with breast cancer. Immunocytochemical staining with HMFG2 antibody over the cell meimbrane and in the cytoplasm of two cancer cells, while surrounding mesothelial cells are unreactive. 


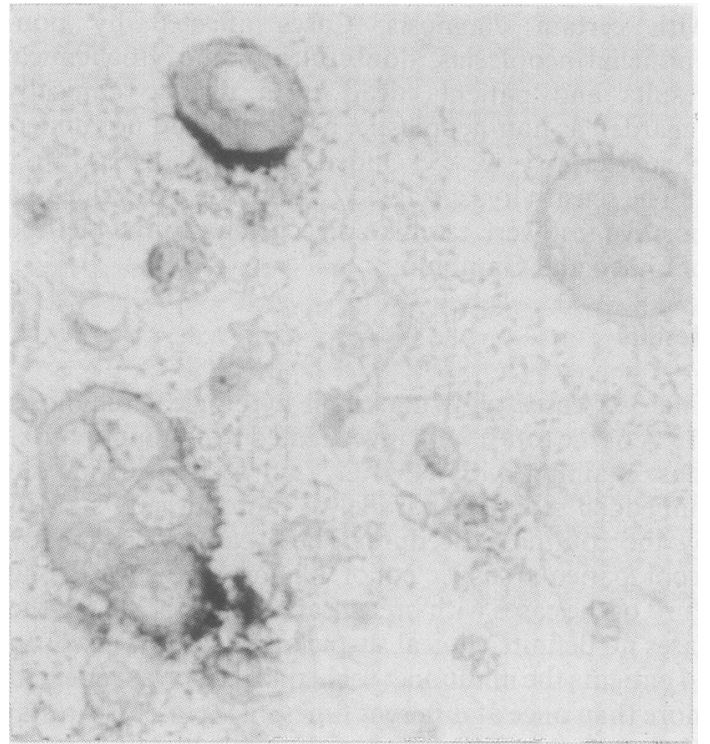

Fig 2 Pleural effusion from a case of mesothelioma. Positive staining with HMFG2 antibody over part of the cell membrane in one isolated and in some clustered cells. A large atypical cell (right) and some reactive cells are unstained.

mesothelial cells were also observed, and constituted a built-in control. The positive cases were from patients affected by breast, lung, ovary, colorectal or gastric cancer and by mesothelioma. Positive staining appeared either as a continuous deposit over the cell surface or a diffuse cytoplasmic staining with or without membrane accentuation (fig 1). Stained cancer cells were isolated or formed solid clusters, morula-like, or arranged blastula-like, around an empty space. In the latter case both the inner and the outer cell surfaces were stained.

A pattern which we came to recognise as typical of mesotheliomas was a lack of correlation between morphology and HMFG2 staining: some highly atypical cells were, in fact, positively stained, others partly stained, and still others completely negative (fig 2). Some benign looking cells of mesothelial type were also stained. Of the 11 cases of mesotheliomas included in this study, only one was HMFG2 negative. This case, on biopsy, showed predominant sarcomatous features. All the cases of mesothelioma were not stained by the CEA monoclonal antibody nor PAS (after diastase). Two of these cases were strongly stained with B72.3 while the rest of the cases had a few atypical cells reacting with $B 72.3$.

In 93 patients ( 108 specimens) which had been rated as "suspect" on the basis of cytology alone, no staining was observed, while in 29 effusions from 18 patients the staining was too weak and the number of positive cells too small (less than 1\%) to allow definite conclusions to be drawn. These latter cases were defined as "inconclusive".

In all patients we checked the clinical diagnosis at discharge from the hospital, which was of breast cancer in 102 patients, ovarian cancer in 22 cases, gastric or colon cancer in 44, lung cancer in 35 , kidney cancer in nine, mesothelioma in 11, non-epithelial tumours (sarcoma, lymphomas) in eight, and "effusion of uncertain nature" in 50 patients. In 15 cases the final clinical diagnosis was of "nonneoplastic" disease.

The reasons for submitting the effusion to cytological diagnosis were different for the various pathological lesions: in many cases and specifically in all breast cancer patients, the request was confirmatory, as they had always been operated on at an earlier date and the effusion appeared as a later development of the disease; in other cases the request was diagnostic. The diagnosis was reached by cytology and immunocytochemistry alone in five cases of ovarian cancer, five cases of gastric or colon cancer, one case of kidney cancer, eight cases of lung cancer, 10 of mesothelioma and in 29 patients with inconclusive clinical diagnosis.

All patients with a final diagnosis of cancer (cases of mesothelioma included) had the diagnosis confirmed by histology, performed before or (in the "diagnostic" cases) after the cytological examination.

Thirty patients died of apparently unrelated car diovascular diseases (18 of cardiac infarction, two os pulmonary embolism, ten of heart failure).

The results of follow up (tables 1-4) indicate that most patients died of cancer shortly after diagnosis. Seventeen patients died of apparently unrelated disease; necropsy was not performed and presence or absence of tumour could not be ascertained. Only 52 patients are still alive and without evidence of neoplastic disease at the time of writing. Thirty four of these had a histologically confirmed diagnosis of cancer; of these, $23 \mathrm{had}$ a positive immunocytochemical diagnosis, three an inconclusive, and eight a negative result. All these patients underwent chemotherapy, hormone therapy, or radiotherapy because of the cytohistological, clinical and radiological evidence of metastases, and their present clinical state is probably related to the therapeutic regimen. No significant

Table 1 Follow up of 296 patients with effusions stained with HMFG2

\begin{tabular}{lrllll}
\hline & & $\begin{array}{l}\text { Death } \\
\text { from } \\
\text { tumour }\end{array}$ & $\begin{array}{l}\text { Death from } \\
\text { non- } \\
\text { neoplastic } \\
\text { causes }\end{array}$ & $\begin{array}{l}\begin{array}{l}\text { Alive } \\
\text { with } \\
\text { tumour }\end{array} \\
\text { Results }\end{array}$ & $\begin{array}{l}\text { Alive } \\
\text { without } \\
\text { tumour }\end{array}$ \\
\hline Positive & 185 & 134 & 17 & 11 & 23 \\
Inconclusive & 18 & 11 & -13 & 4 & 3 \\
Negative & 93 & 49 & 13 & 5 & 26 \\
\hline
\end{tabular}


Table 2 Clinical evaluation at follow up in 185 patients with positive HMFG2 test

\begin{tabular}{|c|c|c|c|c|c|}
\hline Clinical diagnosis & $\begin{array}{l}\text { No of } \\
\text { patients }\end{array}$ & $\begin{array}{l}\text { Death from } \\
\text { tumour }\end{array}$ & $\begin{array}{l}\text { Death from non- } \\
\text { neoplastic disease }\end{array}$ & $\begin{array}{l}\text { Alive with } \\
\text { tumour }\end{array}$ & $\begin{array}{l}\text { Alive without tumour } \\
\text { (after treatment) }\end{array}$ \\
\hline $\begin{array}{l}\text { Breast cancer* } \\
\text { Ovarian cancer* } \\
\text { Stomach and colonic cancer* } \\
\text { Kidney cancer* } \\
\text { Lung cancer } \\
\text { Mesothelioma } † \\
\text { Doubtful }\end{array}$ & $\begin{array}{r}62 \\
18 \\
30 \\
8 \\
28 \\
10 \\
29\end{array}$ & $\begin{array}{r}48 \\
16 \\
20 \\
6 \\
23 \\
6 \\
15\end{array}$ & $\frac{4}{\frac{5}{1}}$ & $\begin{array}{l}3 \\
1 \\
1 \\
4 \\
1 \\
1\end{array}$ & $\begin{array}{l}7 \\
1 \\
4 \\
2 \\
3 \\
6\end{array}$ \\
\hline
\end{tabular}

*All patients underwent surgical treatment

†Confirmed by pleural biopsy.

Table 3 Clinical evaluation at follow up in 18 patients with inconclusive HMFG2 test

\begin{tabular}{lllll}
\hline Clinical diagnosis & $\begin{array}{l}\text { No of } \\
\text { patients }\end{array}$ & $\begin{array}{l}\text { Death from } \\
\text { tumour }\end{array}$ & $\begin{array}{l}\text { Death from non- } \\
\text { neoplastic disease }\end{array}$ & $\begin{array}{l}\text { Alive with } \\
\text { tumour }\end{array}$ \\
\hline Breast cancer & 10 & 5 & - & 2 \\
Ovarian cancer & 1 & 1 & - & - \\
Stomach and colonic cancer & 1 & 1 & - & - \\
Lung cancer & 2 & 2 & - & - \\
Doubtful & 4 & 2 & - & - \\
\hline
\end{tabular}

Table 4 Clinical evaluation at follow up in 93 patients with negative HMFG2 test

\begin{tabular}{|c|c|c|c|c|c|c|}
\hline Clinical diagnosis & $\begin{array}{l}\text { No of } \\
\text { patients }\end{array}$ & $\begin{array}{l}\text { Death from } \\
\text { tumour }\end{array}$ & $\begin{array}{l}\text { Death from non- } \\
\text { neoplastic disease }\end{array}$ & $\begin{array}{l}\text { Alive with } \\
\text { tumour }\end{array}$ & $\begin{array}{l}\text { Alive without tumour } \\
\text { (after treatment) }\end{array}$ & $\begin{array}{l}\text { No evidence } \\
\text { of disease }\end{array}$ \\
\hline $\begin{array}{l}\text { Breast cancer* } \\
\text { Ovarian canncer* } \\
\text { Stomach and colonic cancer* } \\
\text { Kidney cancer* } \\
\text { Lung cancer } \\
\text { Mesothelioma† } \\
\text { Doubtful } \\
\text { Non-epithelial neoplasias } \\
\text { Non-neoplastic cases }\end{array}$ & $\begin{array}{r}30 \\
3 \\
13 \\
1 \\
5 \\
1 \\
17 \\
8 \\
15\end{array}$ & $\begin{array}{r}20 \\
3 \\
12 \\
1 \\
3 \\
1 \\
2 \\
7 \\
-\end{array}$ & $\begin{array}{l}\frac{2}{1} \\
\frac{-}{-} \\
\frac{5}{1} \\
4\end{array}$ & $\begin{array}{l}2 \\
- \\
- \\
\frac{-}{3} \\
-\end{array}$ & $\begin{array}{l}\frac{6}{-} \\
\frac{2}{-} \\
- \\
-\end{array}$ & $\begin{array}{l}- \\
- \\
- \\
\frac{7}{11}\end{array}$ \\
\hline
\end{tabular}

*All underwent surgical treatment

+Confirmed by pleural biopsy.

difference in the development of the neoplastic disease was therefore established between those cancer patients in whom a positive immunocytochemical diagnosis had been made and those with a negative or inconclusive immunocytochemical diagnosis.

Eighteen immunocytochemically negative patients (table 4) were clinically diagnosed as being either free of cancer (11 cases) or doubtful (seven cases): they received no further treatment and are still alive with no evidence of tumour at the time of writing.

The predictive value of a positive HMFG 2 test and the specificity were $100 \%$; the sensitivity was only $41 \%$.

\section{Discussion}

Cytopathological diagnosis of malignant pleural effusions is based on the experience of the examiner and the quality of the cytological technique. ${ }^{6}$ The percentage of reported cytologically positive diag- noses varies from 10 to $49 \%{ }^{67}$ and seems mainly related to patient selection. In cases observed by us between 1984 and 1987, 540 cases, representing $23 \%$ of a total of 2362 effusions examined, were diagnosed as positive for neoplastic cells on the basis of cytology alone.

Besides those cases diagnosed as frankly malignant and those reported as either inflammatory, or reactive, or as serous effusions (with mesothelial cells, lymphocytes and macrophages, or granulocytes as the only cellular components), we considered cases where cells with relatively large and rather hyperchromatic nuclei were encountered in variable numbers. These cells were isolated or occurred in small clusters and could best be defined as suspicious. Similar findings have been reported by Boon et $a l^{2}$ and Hilborne et al. ${ }^{13}$ Such diagnostic problems were, in our series, encountered in $15 \%$ of all effusion specimens sent for cytological examination, a proportion similar to that reported by To et al. ${ }^{7}$ 
Immunocytochemical positive staining with HMFG2 antibody permitted detection of cancer cells in about two thirds of these cases, in agreement with the results of Ghosh ${ }^{510}$ and Hilborne, ${ }^{13}$ who found that staining with this monoclonal antibody increased the detection of carcinoma cells in effusions originally rated as benign or suspicious. In agreement with Epenetos et al, ${ }^{16}$ Marshall et al, ${ }^{22}$ Hilborne et al,,$^{13}$ and Ramaekers et al, ${ }^{1}$ we did not observe expression of HMFG2-related antigen in reactive mesothelial cells. In contrast, Ghosh et al did observe occasional staining of reactive mesothelial cells. ${ }^{23}{ }^{24}$ This discrepancy might be related to differences in procedure (fixation, embedding, staining reaction, antibody concentration).

The use of immunocytochemical procedures has been advocated by several workers ${ }^{1422}{ }^{24-26}$ as helpful in the cytological diagnosis of mesotheliomas, and in the often difficult differential diagnosis from reactive effusions or from metastatic spread from lung adenocarcinomas. ${ }^{327}$ HMFG2-related antigen was expressed in most but not all neoplastic cells present in effusions from the 10 cases of mesothelioma with histological evidence of epithelial differentiation, while the case with sarcomatous differentiation was negative. All these cases were PAS and CEA negative: in agreement with Szpak et $a l^{14}$ we found only occasional cytoplasmic staining with the B72.3 monoclonal antibody.

These immunocytochemical findings are probably related to dual (epithelial and stromal) differentiation of mesothelioma cells in effusions, with only the carcinomatous component (present in variable numbers) being HMFG2 positive and to a minor degree, B72.3 positive. In agreement with Ghosh, ${ }^{24}$ Lauritzen, ${ }^{26}$ and Cibas, ${ }^{25}$ we found that none of the immunocytochemical characteristic of cells in effusions could be regarded as diagnostic; their combination would, however, make the diagnosis of mesothelioma highly probable.

To evaluate the usefulness of immunocytochemistry in resolving suspicious cases, we checked the clinical data. Excellent agreement was found with the clinical diagnosis at discharge (no false positive cases were encountered); but this diagnosis might have been influenced by the response of the cytological laboratory; the clinical outcome therefore constituted a more objective check. No similar studies have been reported since To et al, ${ }^{7}$ Epenetos et al, ${ }^{16}$ Ghosh et al,${ }^{510}$ Menard ${ }^{12}$ Permanetter and Wiesinger, ${ }^{28}$ Hilborne, ${ }^{13}$ Martin, ${ }^{27}$ Johnston $^{15}$ and Lauritzen ${ }^{26}$ referred to cytological or clinical diagnosis to check the value of the immunocytochemical staining.

Complete follow up was possible in 296 of the 307 patients. The original clinical impression was either that of suspected malignant effusion in previously operated on patients, or was derived from routine laboratory procedures. It is interesting to note that 102 cases of "suspicious" effusion were from patients previously operated on for breast cancer (from one to 18 years before). This fact emphasises the well known prevalence of the occurrence of serous effusions in the history of breast cancer patients, a likely sign of relapse. ${ }^{30} 31$ It also confirms the difficulty of recognising metastatic breast cancer cells.

In agreement with Cibas et al, ${ }^{25}$ we found that the examination of sections of the sediment, parallel to that of smears of the same cases, permitted a more precise cytological diagnosis. An additional advantage was that, when a case was regarded as suspicious, new sections could be cut from the embedded sediment and these could be stained by various histochemical and immunocytochemical procedures. Of the 341 effusions from 296 patients included in this study and stained with HMFG2, 230 from 185 patients were reported as positive. Most of these cases were from patients with breast, gastrointestinal, or bronchopulmonary cancer. One hundred and ninety four patients died of cancer after a short interval (from a few months to two years), 30 patients died of apparently unrelated diseases, while 20 patients are still alive with neoplastic disease and receiving treatment.

In $18(6 \%)$ cases the immunocytological diagnosis was reported as doubtful, because of weak staining in only a few cells, while 93 cases were reported as negative. Among these doubtful or negative cases, most were, in fact, cancer patients, who later died of their disease. Cancer cells were either not present in these effusions, or were present but unreactive to HMFG2. This monoclonal antibody recognises ant antigen expressed on epithelial cells, ${ }^{19}{ }^{32}$ but occasional staining of human lymphoid cells has been reported by Delsol et al.$^{33}$ Our specimens from patients affected by sarcomas or lymphomas were negative. Only 15 of the 296 suspicious cases were affected by nonneoplastic diseases and they were correctly diagnosed as immunocytochemically negative.

The specificity of our results was high, in agreement with the data of Hilborne et al. ${ }^{13}$ Our study indicates, ? however, that the clinical impact of immunocytochemical staining is quite modest. We might have expected either result: a worse prognosis in HMFG2 $\delta$ positive cases and the absence of relapse in negative cases, or alternatively more favourable outcome in $\mathrm{O}$ those cases where, thanks to the immunocytochemical staining, a diagnosis had been made and a treatment started accordingly. On the contrary, no difference in $\bar{N}$ disease outcome was found between cancer patients $\Omega$ with a positive or a negative immunocytochemical $N$ diagnosis. Of 102 breast cancer patients; in 62 cases cancer cells were correctly diagnosed by HMFG 2 staining; but in all cases the effusion appeared as an ominous sign of relapse, and the positive diagnosis $\stackrel{\odot}{\odot}$ (and related treatment) did not influence the outcome. $\stackrel{\mathcal{Q}}{\rightarrow}$ Similar conclusions can be reached for diagnoses on 7 effusions occurring in other cancer patients.

HMFG2 staining correctly diagnosed as negative 18 
cases which were regarded as cytologically suspicious; these people were free of cancer and are still alive and well.

In conclusion, immunocytochemical staining with HMFG2 monoclonal antibody permitted specific recognition of cancer cells in about two thirds of the cases which were at best diagnosed as suspicious on the basis of cytology alone; this represents a definite diagnostic gain. In addition, combined cytological and immunocytochemical characteristics (HMFG2 positivity, CEA negativity) meant that the effusions were diagnostic in most cases of mesotheliomas. The impact of the diagnosis on the outcome of the disease was not appreciable.

This work was supported by grants from ARC (Milan), MPI (Rome), and Regione Piemonte.

\section{References}

1 Ramaekers FCS, Vooijs GP, Huijsmans ACLM, Salet-v.d. Pol MRJ, van Aspert-van Erp AJM, Beck HLM. Immunohistochemistry as an aid in diagnostic cytopathology. In: De Lellis RA, ed. Advances in Immunohistochemistry. New York: Raven Press, 1988:133-63.

2 Boon ME, Kwee HS, Alons CL, Morawetz F, Veldhuizen RW. Discrimination between primary pleural and primary peritoneal mesothelioma by morphometry and analysis of vacuolization pattern of the exfoliated mesothelial cells. Acta Cytol 1982;26:103-8.

3 Whitaker D, Shilkin KB. Diagnosis of pleural malignant mesothelioma in life-A practical approach. $J$ Pathol 1984;143: $147-75$.

4 Spriggs AI, Boddington MM. The cytology of effusions. New York: Grune \& Stratton, 1968:12-40.

5 Ghosh AK, Spriggs AI, Taylor-Papadimitriou J, Mason DY. Immunocytochemical staining of cells in pleural and peritoneal effusions with a panel of monoclonal antibodies. J Clin Pathol 1983;36:1154-64.

6 Johnston WW. The malignant pleural effusion. A review of cytopathologic diagnoses of 584 specimens from 472 consecutive patients. Cancer 1985;56:905-9.

7 To A, Coleman DV, Dearnaley DP, Ormerod MG, Steele K, Neville AM. Use of antisera to epithelial membrane antigen for the cytodiagnosis of malignancy in serous effusions. $J$ Clin Pathol 1981;34:1326-32.

8 Mariani-Costantini R, Menard S, Clemente C,Tagliabue E, Colnaghi MI, Rilke F. Immunocytochemical identification of breast carcinoma cells in effusions using a monoclonal antibody. J Clin Pathol 1984;35:1037.

9 Nuti M, Teramoto YA, Mariani-Constantini R, Horan Hand P, Colcher D, Schlom J. A monoclonal antibody (B72.3) defines patterns of distribution of a novel tumor-associated antigen in human mammary carcinoma cell populations. Int $J$ Cancer 1982;29:539-45.

10 Ghosh AK, Mason DY, Spriggs AI. Immunocytochemical staining with monoclonal antibodies in cytologically "negative" serous effusions from patients with malignant disease. $J$ Clin Pathol 1983;36:1150-3.

11 Szpak CA, Johnston WW, Lottich SC, Kufe D, Thor A, Schlom J. Patterns of reactivity of four novel monoclonal antibodies (B72.3, DF3, B1.1 and B6.2) with cells in human malignant and benign effusions. Acta Cytol 1984;28:356-67.

12 Menard S, Rilke F, Torre GD, et al. Sensitivity enhancement of the cytologic detection of cancer cells in effusions by monoclonal antibodies. Am J Clin Pathol 1985;83:571-6.

13 Hilborne LH, Cheng L, Nieberg RK, Lewin KJ. Evaluation of an antibody to human milk fat globule antigen in the detection of metastatic carcinoma in pleural, pericardial and peritoneal fluids. Acta Cytol 1986;30:245-50.

14 Szpak CA, Johnston WW, Roggli V, et al. The diagnostic distinction between malignant mesothelioma of the pleura and adenocarcinoma of the lung as defined by a monoclonal antibody (B72-3). Am J Pathol 1986;122:252-60.

15 Johnston WW. Applications of monoclonal antibodies in clinical cytology as exemplified by studies with monoclonal antibody B72-3. Acta Cytol 1987;31:537-56.

16 Epenetos AA, Canti G, Taylor-Papadimitriou J, Curling M, Bodmer WF. Use of two epithelium-specific monoclonal antibodies for diagnosis of malignancy in serous effusions. Lancet 1982;ii:1004-6.

17 Bussolati G. A celloidin bag for the histological preparation of cytologic material. J Clin Pathol 1982;35:574-6.

18 Heyderman E, Neville AM. A shorter immunoperoxidase technique for the demonstration of carcinoembryonic antigen and other cells products. J Clin Pathol 1977;30:138-40.

19 Arklie J, Taylor-Papadimitriou J, Bodmer WF, Egan M, Millis R. Different antigens expressed by epithelial cells in the lactating breast are also detected in breast cancers. Int $J$ Cancer 1981;28:23-9.

20 Hsu SM, Raine L, Fanger H. Use of avidin-biotin-peroxidase complex $(\mathrm{ABC})$ in immunoperoxidase techniques: a comparison between $A B C$ and unlabelled antibody (PAP) procedures. J Histochem Cytochem 1981;29:577-80.

21 Galen RS, Gambino SR. Beyond normality: the predictive value and efficiency of medical diagnosis. New York: John Wiley \& Sons, 1985.

22 Marshall RJ, Herbert A, Braye SG, Jones DB. Use of antibodies to carcinoembryonic antigen and human milk fat globule to distinguish carcinoma, mesothelioma, and reactive mesothelium. J Clin Pathol 1984;37:1215-21.

23 Ghosh AK, Spriggs AI, Curling M. Tumor markers in serous effusions. Lancet 1984; i:338.

24 Ghosh AK, Gatter KC, Dunnill MS, Mason DY. Immunohistological staining of reactive mesothelium, mesothelioma, and lung carcinoma with a panel of monoclonal antibodies. J Clin Pathol 1987;40:19-25.

25 Cibas ES, Corson JM, Pinkus GS. The distinction of adenocarcinoma from malignant mesothelioma in cell blocks of effusions: the role of routine mucin histochemistry and immunohistochemical assessment of carcinoembryonic antigen, keratin proteins, epithelial membrane antigen, and milk fat globule-derived antigen. Hum Pathol 1987;18:67-74.

26 Lauritzen AF. Distinction between cells in serous effusions using a panel of antibodies. Virchows Arch (Cell Pathol) 1987;411: 299-304.

27 Kwee WS, Veldhuizen RW, Alons CA, Morawetz F, Boon ME. Quantitative and qualitative differences between benign and malignant mesothelial cells in pleural fluid. Acta Cytol 1982;26:401-6.

28 Permanetter $\mathbf{W}$, Wiesinger $\mathbf{H}$. Immunohistochemical study of lysozyme, alpha, -anti-chymotrypsin tissue polypeptide antigen, keratin and carcinoembryonic antigen in effusion sediments. Acta Cytol 1987;31:104-12.

29 Martin SE, Moshiri S, Thor A, Vilasi V, Chu EW, Schlom J. Identification of adenocarcinoma in Cytospin preparations of effusions using monoclonal antibody B72.3. Am J Clin Pathol 1986;86:10-8.

30 Haagensen CD. Diseases of the breast. 2nd Ed. Philadelphia: Saunders Co, 1971.

31 Koss LG. Diagnostic cytology and its histopathologic bases. 3rd Ed Philadelphia: Lipincott Co, 1979.

32 Taylor-Papadimitriou J, Peterson JA, Arklie J, Butchell J, Ceriani RL, Bodmer WF. Monoclonal antibodies to epithelium-specific components of the human milk fat globule membrane: production and reaction with cells in culture. Int $J$ Cancer 1981;28: 17-21.

33 Delsol G, Gatter KC, Stein H, et al. Human lymphoid cells express epithelial membrane antigen. Implications for diagnosis of human neoplasms. Lancet 1984;ii:1124-8.

Requests for reprints to: Professor G Bussolati, Department of Biomedical Sciences and Human Oncology, Section of Pathological Anatomy, Via Santena 7, 10126 Torino, Italy, 